\title{
Measuring social skills: cultural adaptation and validation of SSI-Del Prette
}

João F. Fundinho ${ }^{1 *}$, José Ferreira-Alves ${ }^{1}$, Ana Carolina Braz ${ }^{2}$, Almir del Prette ${ }^{3}$, Zilda del Prette $^{3}$

${ }^{1}$ Escola de Psicologia, Universidade do Minho, Braga, Portugal; ${ }^{2}$ Centro de Psicologia, Universidade do Porto, Porto, Portugal; ${ }^{3}$ Departamento de Psicologia, Relações Interpessoais e Habilidades Sociais, Centro de Educação e Ciências Humanas, Universidade Federal De São Carlos, São Carlos, São Paulo, Brazil

Citation:

Fundinho, J.F., Ferreira-Alves, J., Braz, A.C., Del Prette, Z.A.P. and Del Prette, A. (2021), "Measuring social skills: cultural adaptation and validation of the SSI-Del Prette", The Journal of Adult Protection, Vol. 23 No. 5, pp. 337-350. https://doi.org/10.1108/JAP-032021-0012

Correspondence concerning this article should be addressed to João F. Fundinho, School of Psychology, University of Minho, Campus de Gualtar, 4710-057 Braga, Portugal; Contact: jfmfundinho@gmail.com 
PORTUGUESE ADAPTATION OF SSI-DEL PRETTE

\section{Acknowledgements}

This study was conducted at the Psychology Research Centre (UID/PSI/01662/2013), University of Minho, and supported by the Portuguese Foundation for Science and Technology and the Portuguese Ministry of Science, Technology and Higher Education through national funds and co-financed by FEDER through COMPETE2020 under the PT2020 Partnership Agreement (POCI-01-0145-FEDER-007653). João F. Fundinho was funded by a scholarship from the Portuguese Foundations for Science and Technology - FCT - (PD/BD/105965/2014). 
Measuring social skills: cultural adaptation and validation of the SSI-Del Prette

\begin{tabular}{|r|l|}
\hline Journal: & The Journal of Adult Protection \\
\hline Manuscript ID & JAP-03-2021-0012.R2 \\
\hline Manuscript Type: & Research Paper \\
\hline Keywords: & $\begin{array}{l}\text { social skills, scale adaptation, validation, depression, empathy, } \\
\text { adulthood }\end{array}$ \\
\hline \multicolumn{2}{|l}{} \\
\hline
\end{tabular}

SCHOLARONE ${ }^{m}$

Manuscripts 
Abstract

Purpose: Identifying and assessing social skills has been a powerful way of linking human behaviour and human interaction with their consequences at significant developmental levels. There are some data connecting social skills with interpersonal violence but not yet with elder abuse. The reason might be the scarcity of quick and easy-to-apply measures of social skills. This study aims to adapt and validate the Social Skills Inventory (Del Prette and Del Prette, 2001) to the Portuguese population.

Methodology: We conducted two studies. In study 1, we gathered the psychometric characteristics of the SSI-Del-Prette through exploratory factor analysis (EFA) and confirmatory factor analysis (CFA). In study 2, we correlated the new measure with measures of depression and empathy to test for divergent and concurrent validity.

Findings: The obtained version of the SSI-Del-Prette showed a good model fit and internal consistency. This measure presented six factors: Conversation and social confidence, Easiness of self-exposure, Self-expression of positive affect, Coping assertively with risk, Defending interests and opinions, Giving and receiving praise. The indicators of convergent and divergent validity supported the integrity of the measure.

Originality/value: This paper provides an adaptation of a measure of six social skills expanded to the older adult population.

Research limitations/implications: The adaptation of this measure of social skills opens new possibilities for studying these skills.

Keywords: social skills, scale adaptation, validation, depression, empathy, adulthood 
Measuring social skills: cultural adaptation and validation of the SSI-Del Prette

Probably no one more than Carl Rogers in his seminal work (Rogers, 1957; 1992) stated so powerfully and clearly that, in adult life, the way people relate to each other (which we call social skills) can be (or not be) supportive of human development and change. This support for human development means that people with higher social skills are more caring, more helpful, empathic, and ready to derive meaning from their interactions with others. Although this theory is appealing, it lacks the operationalisation that some authors provided later, pointing to microskills as the central verbal and non-verbal components of facilitating relationships in terms of counselling, psychotherapy, or teaching. However, social skills are not only essential for professionals who use personal relationships as the primary tool of their trade; social skills and interactions are important for every human being because of their role during several developmental stages within their protecting and challenging functions. For some authors, social skills are a determining part of social interactions and are vital as instruments, products, and by-products of different developmental challenges (Riggio et al., 1993).

Beyond their link to human and psychosocial development, social skills (or their absence) are inextricably linked to interpersonal violence. Some authors have found a relationship between deficits in social skills and internalisation of problems, loneliness, depression, anxiety, and problem-solving skills (e.g., Santos and Soares, 2018; Moeller and Seehuus, 2019; Salavera et al., 2019). Research in various contexts has suggested the importance of social skills for risk assessment, prevention, and treatment of some violent situations. In adolescents, social skills training significantly decreases the use of verbal violence (Babakhani, 2011), and children who experience bullying have significantly fewer social skills than children who do not (Fox and Boulton, 2005). Studies about the role of social 
skills in violence with adults are less frequent than studies about the role of social skills in violence with children and adolescents, and studies targeting older adults are even rarer. However, theoretical connections can be established between social skills and elder abuse. Some theoretical hypotheses that attempt to explain elder abuse base their predictions on the caregiver's mental health or experience of stress - situational theory (Moore, 2019). In this regard, a lack of social skills has been related to the emergence of stress and mental health in adults (Segrin, 2017). Other explanations for elder abuse rely on the equilibrium between the perception of benefits and costs in a relationship - Social Exchange Theory (Moore, 2019). The relational competencies of both caregivers and older adults, and consequently social skills, are in this case of great importance for explaining elder abuse. Despite the absence of a clear connection between social skills and elder abuse, caregivers, older adults who receive care, care professionals point to social skills as fundamental for avoiding conflicts in care relationships, especially skills that involve expressing positive feelings, controlling and preventing aggressiveness, and discussing problems (Pinto et al., 2016). One particular social skill has been more frequently used in intervention programmes in the context of older adult caregiving than any other; this social skill is assertiveness. For example, the START programme (Livingston et al., 2013), aimed at promoting mental health among caregivers of family members with dementia, includes a topic about assertive communication. This programme decreases depressive symptomatology and anxiety in family carers, which can be an important risk factor for abuse. Assertive communication has also been the focus of some prevention programmes aimed specifically at preventing elder abuse (Fernández et al., 2012; Hernández et al., 2014), but the effectiveness of the results are not clear. Although assertiveness is an important social skill, it is one of many competencies; the importance of the other skills remains untested and unexplored. 
Finally, we look to social skills as a foundation for best practices in caring for or helping people, mainly older adults. To that end, we will take advantage of the work of Stolee et al. (2012). By searching iteratively in literature reviews, internet reviews and stakeholder opinions, these authors constructed a set of proposals for planning and implementing best practices in the elder abuse domain. Specifically, these authors concluded that there is almost no evidence to carry out actual assessment and intervention strategies within that domain. Therefore, these authors recommended two strategies: "build capacity for research and program evaluation to advance knowledge of effective practices and build capacity for knowledge exchange to enhance professionals' efforts" (p. 180). These recommendations fit very well with the need to translate to practice what we know when we have evidence from good research. If we consider some of the recommendations of Stolee et al. (2012) on what best practices surrounding elder abuse should include, we can see the obvious usability of virtually any measure of social skills. Their recommendations are: (a) "include the perspectives of older adults and victims in research, evaluation, and policy and procedure development"; (b) "use a client-centred approach (not "one size fits all")"; (c) consider gender, family violence, and intergenerational approaches; (d) "be sensitive to variations in language, culture, ethnicity, religion, and Aboriginal identity"; and finally (e) "ensure coordination and integration across professionals/organisations" (p. 185). What could be a more direct way to train professionals (e.g., social workers, physicians, psychologists, nurses, and even researchers) within the scope of these recommendations than social skill education and training?

In summary, we have enough evidence that social skills affect psychosocial development processes, the understanding and planning prevention of interpersonal violence, and implementing best practices within health and social care systems. 
In the present paper, we aim to present psychometric data for a measure of social skills, the Social Skills Inventory-Del Prette (Del Prette and Del Prette, 2001), collected from a Portuguese sample.

Del Prette and Del Prette defined social skills as "a descriptive construct of the social behaviours valued in a particular culture with a high probability of favourable results for the individual, group and community that may contribute to a socially responsible performance in interpersonal tasks" (Del Prette and Del Prette, 2018a, p. 24). From this conceptual standpoint, it is possible to classify social skills by their form (e.g. tone of voice, gestures, facial expressions) and functionality. Additionally, behaviours may have a similar function but might vary in form (Del Prette and Del Prette, 2018a), which means that our social behaviour can vary quite a bit without changing its function.

Another aspect to consider is the intimate relationship between social behaviours and social habits, making culture a determinant of the form and function of social skills. Cultural practices shape our social behaviour and influence social skills' behavioural representations (Del Prette and Del Prette, 2013). Additionally, social skills are ways of adaptation and coping. These are reasons enough to justify validating social skills measures, even from same-language countries, such as Portugal and Brazil.

In the following paragraphs, we will present the measure for which we ran procedures of adaptation and validation.

\section{The Social Skills Inventory - Del Prette}

The Social Skills Inventory - Del Prette (Del Prette and Del Prette, 2001) is a self-report instrument widely used in Brazil (Del Prette and Del Prette, 2019); it assesses a range of social skills required in several kinds of everyday interpersonal situations. The items describe different skills in distinct contexts and their use in different interpersonal relationships. 
The scale's original factor structure was composed of five factors, described by Del Prette and Del Prette (2013). These factors represent classes of social skills, mainly organised by the functionality of the behaviour. The first factor is "Coping and self-assertion with risk", referring to the skills needed to deal with interpersonal situations with assertiveness, entailing the possibility of an aversive reaction of the interlocutor (e.g. Item 16: "In a group of known people, if I do not agree with the majority, I verbally express my disagreement"). The second factor is "Self-assertion in the expression of positive affect" and involves skills related to the expression of positive affect, showing appreciation and respect for others (e.g. Item 10: "I express affection by words or gestures to my family, friends and colleagues"). The third factor is "Conversation and social confidence" and consists of skills required to conduct and maintain a neutral social relationship, denoting knowledge of usual standards on daily relationships (e.g. Item 1: "In a group of unknown people, I am at ease, talking naturally"). The fourth factor, "Self-exposure to unknown people and new situations", comprises skills to approach unknown people (e.g. Item 23: "I avoid asking questions to unknown people”). This factor is somewhat similar to the previous one but encompasses higher risk and exposure. The fifth factor, "Self-control of aggressiveness", aggregates skills to control one's anger and aggressiveness in aversive situations (e.g. Item 18- "When one of my relatives criticises me for some reason, I react aggressively").

The original scale aimed to assess adults between 18 and 25 years old, and it was later extended to 59 years old (Del Prette and Del Prette, 2018b). Additionally, there is a version explicitly directed toward older adults, with differently worded items, removing references to school or work environments to target the elderly population (Braz et al., 2013). Given that some stability is expected in the performance of social skills classes, we opted to design a single version scale for those ages 18 and up. A possible disadvantage is that a single version, analytically speaking, is likely to focus on behaviours that remain more stable across the 
lifespan, thus focusing on skills that are less prone to change and, as a result, the measure will most likely have fewer items. Nevertheless, this version can be an important tool for exploring and understanding the relationship between social skills and human development.

We present the data from this adaptation and validation in two studies. Study 1 focused only on the cultural adaptation of the SSI-Del-Prette and its psychometric characteristics. Study 2 centred on convergent and divergent validity by relating the factorial structure obtained in study 1 with two measures: a measure of empathy and one of depression.

\section{Study 1}

The first study aimed to find a factorial structure of the SSI-Del-Prette for the Portuguese population and its associated psychometric characteristics.

\section{Participants}

Given the possible cultural variations in social behaviours, we opted for cross-validation. We gathered data from 287 participants, $215(74.9 \%)$ of whom were female, ranging in age from 19 to 94 years ( $M=41.23$; $\mathrm{SD}=23.26)$. Regarding marital status, 152 (53\%) of the participants were single, 83 (28.9\%) were married, 27 (9.4\%) were widowers/widows, and 25 $(8.7 \%)$ were divorced. Regarding education level, 10 (3.5\%) participants attended but did not complete elementary school, 44 (15.3\%) did complete elementary school, 6 (2.1\%) completed middle school, 115 (40.1\%) completed high school, and 112 (39\%) had a university degree. We screened participants 65 or older for cognitive impairment using the Mini-Mental State Examination (Folstein et al., 1975, Portuguese version by Guerreiro et al., 1994). We recruited participants online. We also recruited older adult participants from social recreational centres. We randomly divided the dataset into two datasets, accounting for demographics, thereby splitting the dataset into two demographically equivalent data sets: dataset $1(n=141)$ for exploratory factor analysis (EFA) and dataset $2(n=146)$ for confirmatory factor analysis (CFA). 


\section{Procedure}

We collected the participants' answers as part of a larger investigation that was submitted and approved by an ethics committee. Three formats were used: online, paper-and-pencil, and a touchscreen system with the read-aloud option. The answering time for SSI-Del-Prette (Del Prette and Del Prette, 2001) varied due to the data collection method and across age groups; older participants were prone to thinking more cautiously about each question, thus taking longer. In general, it took between 8 and 25 minutes to answer all the items.

\section{Measures}

For this validation, we used the 38 items of the SSI-Del-Prette (Del Prette and Del Prette, 2001). The items were subjected to two adaptations: a) we made small changes in wording so that the item's wording could be closer to the use of the Portuguese language in Portugal; and b) given the goal of producing a single version to be applied across the entire adult lifespan, we removed references to places more commonly frequented by a given age group (e.g. references to school). We sent our adaptations back to the original authors, who approved them before application. Participants marked the frequency with which they performed the behaviour described in each item on a 5 -point Likert scale $(1=$ Never or rarely to $5=$ always or almost always).

\section{Data Analysis}

We conducted statistical analysis using the Statistical Package for the Social Sciences (SPSS) and AMOS, both from IBM (version 24).

First, we scanned the collected data for missing data, outliers and normality. We also transformed the scores of reverse worded items. We conducted EFA using dataset 1 and CFA using dataset 2. We performed EFA with maximum likelihood estimation and Promax rotation. To assess the fit of the model obtained during CFA, we calculated the standardised root mean square residual (SRMR), the root mean square error of approximation (RMSEA), 
the comparative fit index (CFI), and the $\chi 2 /$ d.f. (chi-square/degrees of freedom). We tested two models using CFA: the model obtained through EFA and a theory-driven model. We built the theory-driven model respecting the original structure of the scale and considering our samples' cultural differences. The theory-driven model has six factors developed from 22 of the original items: Factor 1 is "Conversation and social confidence", representing behaviours about being at ease during social interactions; Factor 2 is "Easiness of selfexposure" regarding familiar and unfamiliar situations where the respondent might feel socially exposed; Factor 3 is 'Self-expression of positive affect', which entails items related to the self-expression of affection; Factor 4 is "Coping assertively with risk", with the common theme of behaving assertively in risky situations; Factor 5 is "Defending interests and opinions", which is related to defending one's and other's interests, a sort of assertiveness that encompasses a sense of justice and has a higher risk of confrontation; and Factor 6 is "Giving and receiving praise", which is exclusively related to giving and receiving praise.

\section{Results}

\section{Exploratory factor analysis.}

The first outcome of EFA was Bartlett's test of sphericity, which was significant $\left(\chi^{2}(325)=1135.969, p<.001\right)$, indicating the appropriateness of using EFA on this dataset and the Kaiser-Meyer-Olkin indicated middling sampling adequacy $(\mathrm{KMO}=.739)$. The final fivefactor solution had 26 items, explaining $40.306 \%$ of the variance. Table I displays the rotated pattern matrix.

----Insert Table I----

The five factors extracted from EFA did not clearly reflect a theoretically solid factor structure. For example, Factor 2 was composed of items regarding the expression of 
affection, but it had an off-the-topic item, namely, Item 21 , which states - "When receiving a defective product, I go back to the store and demand a replacement”.

\section{Confirmatory factor analysis.}

We adopted a competing model approach, testing two models: the model extracted through EFA and the theory-driven model. Fit indexes for both models can be found in Table II.

---Insert Table II--

Regarding the model's fit, the EFA model does not achieve enough indicators to be considered an acceptable solution. The theory-driven model, however, achieved the minimum fit indicators and was considered an acceptable solution.

In the theory-driven model, items presented adequate loadings for their respective factors, and internal consistency was acceptable (total scale Cronbach's alpha=.797). The factor loadings and internal consistency of the subscales are presented in Table III.

---Insert Table III---

\section{Discussion}

The main objective of study 1 was to find a factorial structure for the SSI-Del-Prette (Del Prette and Del Prette, 2001) and its psychometric characteristics using data collected in Portugal. As previously argued, there could be cultural differences that affect our social behaviour; therefore, we opted to perform exploratory and confirmatory factor analysis. The EFA was helpful, but it was necessary to perform a careful analysis of each item's content and the patterns presented to generate a theoretically defendable model. This theoretical model achieved adequate fit; therefore, it is an acceptable model to assess social skills in the Portuguese population based on the items of the original SSI-Del-Prette (Del Prette and Del Prette, 2001). 
The resulting model has some similarities with and differences from the original scale's structure. Four factors of our version are conceptually identical to four factors of the original scale ("Conversation and social confidence", "Easiness of self-exposure", "Self-expression of positive affect", and "Coping assertively with risk"). Here, unlike in the original works of Del-Prette and Del-Prette (2001), we did not find a factor for "Self-control of aggressiveness"; however, we found a factor related to protecting one's opinion, a narrower form of assertiveness, with higher stakes. We called it "Defending interests and opinions". A certain degree of control of aggressiveness is implicit in this new factor so that it might be, to some degree, related to the factor in the original proposal. The main difference was our sixth factor, "Giving and receiving praise". This new factor has been considered since in the more recent works of Del Prette and Del Prette (2018a); giving and presenting praise is mentioned in two different sections of the social skills portfolio (Communication and Making and Maintaining Friends). Overall, the obtained factor structure was close enough to the original one to support the idea of universality in social skills and different enough to support the argument that there are cultural specificities in social behaviour.

\section{Study 2}

This study focused on the convergent and divergent validity of the Portuguese adaptation of the SSI-Del-Prette, namely, by correlating our obtained measure outcomes with two indices: depression and empathy.

The role of social skills in depression is frequently examined but is not completely clear. For instance, differences in social skills between adolescents with and without depressive symptoms also relate to gender (Campos et al., 2018). However, several theoretical relationships between social skills and depression have been proposed (Segrin, 2000); the exact role of social skills in depression remains unclear. For example, Segrin et al., (2016) used depression as one of several psychological distress indicators and found a negative 
association between psychological distress and social skills. Although the relationship between social skills and depressive symptoms is not clear, the direction of this relationship seems negative; therefore, we chose depressive symptomatology as an indicator of divergent validity.

We chose empathy as an indicator of convergent validity because empathy, as Davis (1983, p. 113) put it, "refers to the reactions of one individual to the observed experiences of another". Therefore, by definition, successfully using social skills is associated with the ability to react to others' experiences; therefore, a positive relationship is expected between them. Some authors consider empathy to be a behavioural portfolio's primary social skill (Del Prette and Del Prette, 2018a). Moreover, empathy measures are standard benchmarks of convergent validity for measures of social skills (e.g. Anastácio et al., 2016).

\section{Participants and Procedure}

A total of 212 participants ranging in age from 19 to 68 years $(M=31.29 ; \mathrm{SD}=12.98), 172$ $(81.1 \%)$ of whom were female, and also participated in study 1 , completed the measures of depression and empathy, in addition to the items of the SSI-Del-Prette, taking 20 minutes on average. Regarding demographic traits, participants' marital status indicated that 137 (64.6\%) were single, 57 (26.9\%) were married, $17(8 \%)$ were divorced, and $1(0.5 \%)$ was widowed. Regarding education level, 1 (0.5\%) completed middle school, 109 (51.4\%) completed high school, and the remaining $102(48.1 \%)$ had a university degree.

\section{Measures}

In this study, we used the version of the SSI-Del-Prette (Del Prette and Del Prette, 2001) generated in study 1 . We calculated a total scale score and factor scores, as described in study 1.

To measure empathy, we used the Interpersonal Reactivity Index (IRI; Davis, 1983; the Portuguese version for research by Ferreira-Alves et al., 2012). This measure has 28 items 
describing behaviours and emotions based on 4 dimensions of empathy: Perspective-taking, Fantasy, Empathic concern and Personal distress. The participants answered each item on a six-point Likert scale, from 1 (Does not describe me well) to 6 (Describes me very well).

We assessed depressive symptomatology using Beck’s Depression Inventory (BDI; Beck et al., 1961, the Portuguese version by Coelho et al., 2002). This measure has 21 items, where each alternative presents a higher level of depression than the previous measure. The total score varies from 0 to 63 points.

\section{Data Analysis}

First, we performed CFA on all measures, as Hair et al. (2014) suggested as a good practice, following the same guidelines as in study 1. Second, we observed descriptive statistics of all of measures. Third, we used Pearson correlations to check the relationship between our version of the SSI-Del-Prette and the variables of Empathy and Depression.

\section{Results}

First, to confirm the factor structure of IRI, we conducted CFA. The four-factor structure presented acceptable model fit $(\chi 2=96.409, d f=48, p<.001, \mathrm{CFI}=.926$; RMSEA $=.069$; $\mathrm{SRMR}=.061$ ). Internal consistency was acceptable (full-scale Cronbach's $\alpha=.788$; Fantasy $\mathrm{CR}=.66$; Empathic concern $\mathrm{CR}=.73$; Perspective-taking $\mathrm{CR}=.73$; Personal Distress $\mathrm{CR}=.75$ ).

The BDI showed a previously reported two-factor (somatic-affective factor and cognitive factor) structure (Arnau et al., 2001) with good model fit $(\chi 2=292.280, d f=166, p<.001$, $\mathrm{CFI}=.900 ; \mathrm{RMSEA}=.060 ; \mathrm{SRMR}=.060)$. It also showed good internal consistency (full-scale Cronbach's $\alpha=.895$; somatic-affective factor $\mathrm{CR}=.85$; cognitive factor $\mathrm{CR}=.77$ ). Descriptive statistics for all three measures are displayed in Table IV.

---Insert Table IV---

To test for convergent and divergent validity, we correlated the measure of depressive symptomatology (BDI) and the measure of empathy (IRI) with the social skills measured by 
the SSI-Del-Prette. We expected that social skills would be positively associated with empathy and negatively associated with depressive symptoms, as previously justified. Table $\mathrm{V}$ presents the correlation coefficients between the SSI-De-Prette and the IRI and the BDI. ---Insert Table V---

The main results indicate a negative correlation between the BDI and the SSI-De-Prette total score, and negative correlations between the BDI and "Conversation and social confidence”, "Easiness of self-exposure”, and "Coping assertively with risk”. "Selfexpression of positive affect", "Defending interests and opinions", and "Giving and receiving praise" did not correlate with the BDI. The BDI subscales showed the same pattern, except for cognitive symptoms, which did not correlate significantly with

\section{"Conversation and social confidence".}

Like in opposition, the total score for empathy correlated significantly and positively only with "Self-expression of positive affect", "Defending interests and opinions", and "Giving and receiving praise”. The IRI subscales revealed a more complex pattern. Fantasy did not correlate significantly with any indicator of the SSI-Del-Prette. Empathic concern showed the opposite pattern of the cognitive symptomatology subscale: it correlated positively with the total scale and "Conversation and social confidence", "Self-expression of positive affect", "Defending interests and opinions", and "Giving receiving praise" and did not correlate with "Easiness of self-exposure" and "Coping assertively with risk". Perspective-taking correlated positively with all indicators of the SSI-Del-Prette. Personal distress revealed a similar pattern to the BDI and negatively with "Defending interests and opinions".

\section{Discussion}

The main objective of study 2 was to present indicators of convergent and discriminant validity for our newly adapted SSI-Del-Prette. First, we tested the structure of the measures used for convergent and discriminant validity and deemed them acceptable. Second, we 
examined the descriptive statistics of the BDI and the IRI. Third, we correlated the measures as indicators of convergent and discriminant validity.

The obtained results are congruent with the expected relations between the measures. Depressive symptomatology and social skills do not always have a clear relationship (Campos et al., 2018; Segrin, 2000). Our results suggest that for depressive symptoms, social skills might perhaps adopt a mediating role between depressive symptoms and other variables. We found negative correlations between depressive symptoms and "Conversation and social confidence", "Easiness of self-exposure", and "Coping assertively with risk", but not with "Self-expression of positive affect", "Defending interests and opinions", or "Giving and receiving praise”. These results are congruent with Segrin et al. (2016), who proposed that depressive symptoms could relate to social skills but only as part of distress since the related factors seem to be the ones more likely to cause distress. A surprising outcome is the lack of relationship between the somatic-affective subscale and "Self-expression of positive affect". Perhaps there is a difference between experiencing affective symptoms of depression and expressing affection to others.

For the empathy measure, there was no correlation between the measures' total scores, while we expected a positive association. This result might be because the total IRI score includes the score of Fantasy, which showed no relationship with social skills. The absence of a relation between Fantasy and social skills seems reasonable since no theoretical reason for this relationship exists. The relationships found with Empathic Concern make sense; the one relationship that could seem odd is with "Defending interests and opinions", but this factor has an item about other people's interests; therefore, some level of empathic concern is understandable. Perspective-taking is associated with all the SSI-Del-Prette indicators, which makes sense as taking the perspective of the people we interact with is essential to all the assessed skills. Last, the only difference between personal distress and the BDI is the 
negative relation with "Defending interests and opinions". This factor might lead to confrontation; this does not necessarily cause depressive symptomatology but quite likely causes personal distress. Hence, there is some logic in this outcome.

The obtained correlations, in our view, support the discriminant and convergent validity of the SSI-Del-Prette, adding arguments in favour of its use.

\section{General Discussion}

The purpose of this article was to present a cultural adaptation of the SSI-Del-Prette (Del Prette and Del Prette, 2001) for the Portuguese population and its psychometric characteristics. Moreover, we intended to show some evidence of the resulting measure's divergent and convergent validity by associating it with a measure of depression and one of empathy.

Due to cultural influence, social skills provide a challenge when one wants to validate measurement instruments (Del Prette and Del Prette, 2013). Nevertheless, the variety of social skills training programmes (e.g. Braz et al., 2013; Turner et al., 2018) and the other research possibilities that emerge from this measure make its validation meaningful. However, a difficulty inherent in measures based on cultural behaviours is that they are everchanging, making the process of adaptation and validation never definitive but always subject to re-evaluation.

Regarding the convergent and divergent validity, the obtained results, as explored previously, were as expected and contribute as an indicator of quality for our version of the SSI-Del-Prette.

However, this validation presents some limitations. First, we did not test the test-retest reliability, as was done with the original version (Bandeira et al., 2000). It is fundamental to test for temporal stability of a measure that can be used to gauge interventions. The second limitation is the absence of a comparison of the scale performance between genders. This 
comparison was not on our objective for this paper, but there could be gender differences in the use of social skills. Testing the metric invariance of this measure would clarify whether this version works equally well for men and women. We did not perform such a test due to the small number of male participants. Third, as an adaptation of a measure, we could have overlooked behaviours that are more common in the Portuguese population, which are part of the assessed social skills but were not present in the original items. Although Portugal and Brazil share a language, there are enough differences in social behaviour to suggest that some extra items could lead to a more similar set of classes as the ones suggested by the original authors (Del Prette and Del Prette, 2018b), even if our behavioural portfolios might vary.

\section{Conclusion}

In summary, we generated a measure with good indexes of internal validity; this means that people reply differentially according to the dimensions of "Conversation and social confidence", "Easiness of self-exposure", "Coping assertively with risk", "Self-expression of positive affect", "Defending interests and opinions", and "Giving and receiving praise". Further, we obtained good indexes of external validity because this measure was significantly and positively linked to empathic concern and perspective-taking and negatively related to personal distress and depression.

In our view, the measure validated in this paper and other measures of the same nature can be important tools to develop and assess intervention, prevention, and training programmes for professional or voluntary carers aimed at safeguarding adults. Although assertiveness has been a competence of interest for interventions with caregivers and older adults (e.g. Livingston et al., 2013; Hernández et al., 2014), other social skills may have a relevant role to play. The training and promotion of social competence can very well be a way to prevent elder abuse since it emerges in social relationships. Enhancing social skills can also be of value for the training of social and health professionals that work in adult protection. Social 
skills can be important competencies for professionals, contributing to better communication with patients and clients. These skills have the potential to enhance these interactions and perhaps even contribute to building safer social environments between professionals and adult victims.

The previously stated connections between the social skills of professional caregivers, or even older adults themselves, regarding the quality of adult care provide a foundation for many future studies within the field as action research. The inclusion of social skills in the education of professionals can, in our view, benefit the realm of adult protection. A first step, however, needs to be the creation, adaptation, and validation of measures. We hope that this paper can provide researchers and professionals with an alternative to measure social skills and inspire the inclusion of these variables in the sphere of professional education to achieve adult protection. 


\section{References}

Anastácio, S., Vagos, P., Nobre-Lima, L., Rijo, D. and Jolliffe, D. (2016), “The Portuguese version of the Basic Empathy Scale (BES): Dimensionality and measurement invariance in a community adolescent sample", European Journal of Developmental Psychology, Vol. 13 No. 5, pp. 614-623.

Arnau, R.C., Meagher, M.W., Norris, M.P. and Bramson, R. (2001), "Psychometric evaluation of the Beck Depression Inventory-II with primary care medical patients", Health Psychology, Vol. 20 No. 2, pp. 112-119.

Babakhani, N. (2011), "The effects of social skills training on self-esteem and aggression male adolescents”, Procedia - Social and Behavioral Sciences, Vol. 30, pp. 1565-1570.

Bandeira, M., Costa, M.N., Del Prette, Z.A.P., Del Prette, A. and Gerk-Carneiro, E. (2000), “Qualidades psicométricas do Inventário de Habilidades Sociais (IHS): estudo sobre a estabilidade temporal e a validade concomitante", Estudos de Psicologia (Natal), Vol. 5 No. 2, pp. 401-419.

Beck, A.T., Ward, C.H., Mendelson, M., Mock, J. and Erbaugh, J. (1961), “An inventory for measuring depression”, Archives of General Psychiatry, Vol. 4 No. 6, pp. 561-571.

Braz, A.C., Del Prette, Z.A. and Del Prette, A. (2013), “Assertive social skills training for elderly”, Revista Internacional de Psicología Clínica y de La Salud, Vol. 19 No. 2, pp. $373-387$.

Campos, J.R., Del Prette, Z.A.P. and Del Prette, A. (2018), "Relações entre depressão, habilidades sociais, sexo e nível socioeconômico em grandes amostras de adolescentes”, Psicologia: Teoria e Pesquisa, Vol. 34.

Coelho, R., Martins, A. and Barros, H. (2002), “Clinical profiles relating gender and depressive symptoms among adolescents ascertained by the Beck Depression Inventory II", European Psychiatry, Vol. 17 No. 4, pp. 222-226. 
Davis, M.H. (1983), "Measuring individual differences in empathy: Evidence for a multidimensional approach", Journal of Personality and Social Psychology, Vol. 44 No. 1, pp. 113-126.

Del Prette, A. and Del Prette, Z. (2018a), Competência Social e Habilidades Sociais: Manual Teórico-Prático, Edição Dig., Editora Vozes, Petrópolis, RJ.

Del Prette, Z.A.P. and Del Prette, A. (2001), Inventário de Habilidades Sociais (IHS-DelPrette): Manual de Aplicação, Apuração e Interpretação, Casa do Psicólogo, São Paulo.

Del Prette, Z.A.P. and Del Prette, A. (2013), “Social skills inventory (SSI-Del-Prette): Characteristics and studies in Brazil”, Social Anxiety Disorder: From Research to Practice, pp. 47-62.

Del Prette, Z.A.P. and Del Prette, A. (2018b), Inventario de Habilidades Sociais (IHS2-DelPrette): Manual de Aplicação, Apuração e Interpretação, Pearson Clinical do Brasil, São Paulo.

Del Prette, Z.A.P. and Del Prette, A. (2019), "Studies on Social Skills and Social Competence in Brazil: A History in Construction", Psychology in Brazil, pp. 41-66.

Fernández, S., Pérez, Y., Mediciego, B.F.- and 2012, U. (2012), 'Educative intervention program to promote assertive conducts in elderly persons', Mediciego, Vol. 18 No. 2.

Ferreira-Alves, J., Nascimento, M.Â.P.B. do, Cardeira, L., Campos, A. and Grace, R. (2012), Índice de Reatividade Pessoal (IRI): Versão de Investigação, Universidade do Minho. Folstein, M.F., Folstein, S.E. and McHugh, P.R. (1975), ““Mini-mental state'. A practical method for grading the cognitive state of patients for the clinician", Journal of Psychiatric Research, Vol. 12 No. 3, pp. 189-198.

Fox, C.L. and Boulton, M.J. (2005), “The social skills problems of victims of bullying: Self, peer and teacher perceptions", British Journal of Educational Psychology, Vol. 75 No. 2, pp. 313-328. 
Guerreiro, M., Silva, A.P., Botelho, M.A., Leitão, O., Castro-Caldas, A. and Garcia, C. (1994), “Adaptação à população portuguesa da tradução do Mini Mental State Examination (MMSE)”, Revista Portuguesa de Neurologia, Vol. 1 No. 9, pp. 9-10.

Hair Jr, J.F., William, C., Babin, B.J. and Anderson, R.E. (2014), Multivariate Data Analysis - Pearson New International Edition, 7th ed., Pearson Education Limited.

Hernández, Y. D., Sóñora, L. M., Leal, A. I. O., Alvarez, C. M., Ledón, Y. A. and Ocaña, L. M. (2014), 'Diseño de una intervención educativa para prevenir y controlar la violencia contra adultos mayores de una población de Ciego de Ávila', Mediciego, Vol. 20 No. 2. Livingston, G., Barber, J., Rapaport, P., Knapp, M., Griffin, M., King, D., Livingston, D., et al. (2013), 'Clinical effectiveness of a manual based coping strategy programme (START, STrAtegies for RelaTives) in promoting the mental health of carers of family members with dementia: pragmatic randomised controlled trial', BMJ (Clinical Research Ed.), Vol. 347, p. f6276.

Moeller, R.W. and Seehuus, M. (2019), 'Loneliness as a mediator for college students' social skills and experiences of depression and anxiety', Journal of Adolescence, Academic Press, Vol. 73, pp. 1-13.

Moore, S. (2019), "The relativity of theory: applying theories of social psychology to illuminate the causes of the abuse of older people in care homes", The Journal of Adult Protection, Vol. 21 No. 2, pp. 89-110.

Pinto, F.N.F.R., Barham, E.J. and Del Prette, Z.A.P. (2016), “Interpersonal conflicts among family caregivers of the elderly: The importance of social skills", Paideia, Vol. 26 No. 64, pp. 161-170.

Riggio, R.E., Watring, K.P. and Throckmorton, B. (1993), "Social skills, social support, and psychosocial adjustment", Personality and Individual Differences, Vol. 15 No. 3, pp. $275-280$. 
Rogers, C.R. (1952), ““Client-Centered” Psychotherapy’, Scientific American, Vol. 187 No. 5, pp. 66-75.

Rogers, C.R. (1992), 'The Necessary and Sufficient Conditions of Therapeutic Personality Change', Journal of Consulting and Clinical Psychology, Vol. 60 No. 6, pp. 827-832.

Salavera, C., Usán, P. and Teruel, P. (2019), 'The relationship of internalising problems with emotional intelligence and social skills in secondary education students: gender differences', Psicologia: Reflexao e Critica, Vol. 32 No. 1.

Santos, Z. A. and Soares, A. B. (2018), 'Social skills, coping, resilience and problem-solving in psychology university students', Liberabit: Revista Peruana de Psicología, Vol. 24 No. 2, pp. 265-276.

Segrin, C. (2000), "Social skills deficits associated with depression”, Clinical Psychology Review, Vol. 20 No. 3, pp. 379-403.

Segrin, C. (2017), "Indirect effects of social skills on health through stress and loneliness", Health communication, Vol. 34 No. 1, pp. 118-124.

Segrin, C., Mcnelis, M. and Swiatkowski, P. (2016), "Social Skills, Social Support, and Psychological Distress: A Test of the Social Skills Deficit Vulnerability Model”, Human Communication Research, Vol. 42 No. 1, pp. 122-137.

Stolee, P., Hiller, L.M., Etkin, M. and McLeod, J. (2012), “"Flying by the Seat of Our Pants”: Current Processes to Share Best Practices to Deal With Elder Abuse', Journal of Elder Abuse and Neglect, Vol. 24 No. 2, pp. 179-194.

Turner, D.T., McGlanaghy, E., Cuijpers, P., Van Der Gaag, M., Karyotaki, E. and MacBeth, A. (2018), “A Meta-Analysis of Social Skills Training and Related Interventions for Psychosis", Schizophrenia Bulletin, Vol. 44 No. 3, pp. 475-491. 


\section{PORTUGUESE ADAPTATION OF SSI-DEL PRETTE}

Table I

Factor loadings from EFA extracted with maximum likelihood and Promax rotation.

\begin{tabular}{|c|c|c|c|c|c|}
\hline Item & Factor 1 & Factor 2 & Factor 3 & Factor 4 & Factor 5 \\
\hline Item 23 & .736 & -.060 & -.044 & -.098 & -.088 \\
\hline Item 36 & .683 & .150 & -.020 & -.163 & .088 \\
\hline Item 9 & .630 & -.015 & -.059 & -.091 & -.094 \\
\hline Item 17 & .519 & -.161 & -.065 & .187 & -.266 \\
\hline Item 12 & .479 & .106 & .072 & .012 & .029 \\
\hline Item 1 & .431 & .364 & .013 & -.127 & .115 \\
\hline Item 14 & .426 & -.160 & .290 & .055 & .123 \\
\hline Item 8 & .418 & .064 & .125 & .030 & .076 \\
\hline Item 30 & .377 & -.087 & .143 & .287 & -.021 \\
\hline Item 13 & .377 & .051 & -.206 & .045 & .223 \\
\hline Item 26 & .257 & -.182 & .064 & -.036 & .121 \\
\hline Item 7 & .094 & .732 & -.068 & -.102 & -.118 \\
\hline Item 31 & -.179 & .539 & -.058 & .036 & .361 \\
\hline Item 20 & .043 & .495 & -.029 & .136 & .036 \\
\hline Item 10 & -.097 & .485 & .056 & .272 & .009 \\
\hline Item 21 & -.157 & .385 & .222 & .037 & -.091 \\
\hline Item 15 & -.074 & -.033 & .861 & -.265 & .105 \\
\hline Item 16 & .044 & -.113 & .792 & .109 & .131 \\
\hline Item 11 & .008 & .113 & .530 & .228 & -.163 \\
\hline Item 27 & .051 & .343 & .485 & -.099 & -.165 \\
\hline Item 28 & .022 & -.077 & -.105 & .734 & .218 \\
\hline Item 25 & -.224 & .102 & -.042 & .593 & -.048 \\
\hline Item 29 & .101 & .271 & .066 & .482 & -.103 \\
\hline Item 3 & -.045 & -.143 & .049 & .012 & .822 \\
\hline Item 32 & .034 & .143 & .031 & .061 & .428 \\
\hline Item 6 & .122 & .287 & .003 & .159 & .301 \\
\hline $\begin{array}{l}\% \text { of variance } \\
\text { explained }\end{array}$ & 17.142 & 8.96 & 6.523 & 3.993 & 3.688 \\
\hline
\end{tabular}

Bold values represent loadings higher than .25 . 
PORTUGUESE ADAPTATION OF SSI-DEL PRETTE

Table II

$C F A$ results for the theory-driven model

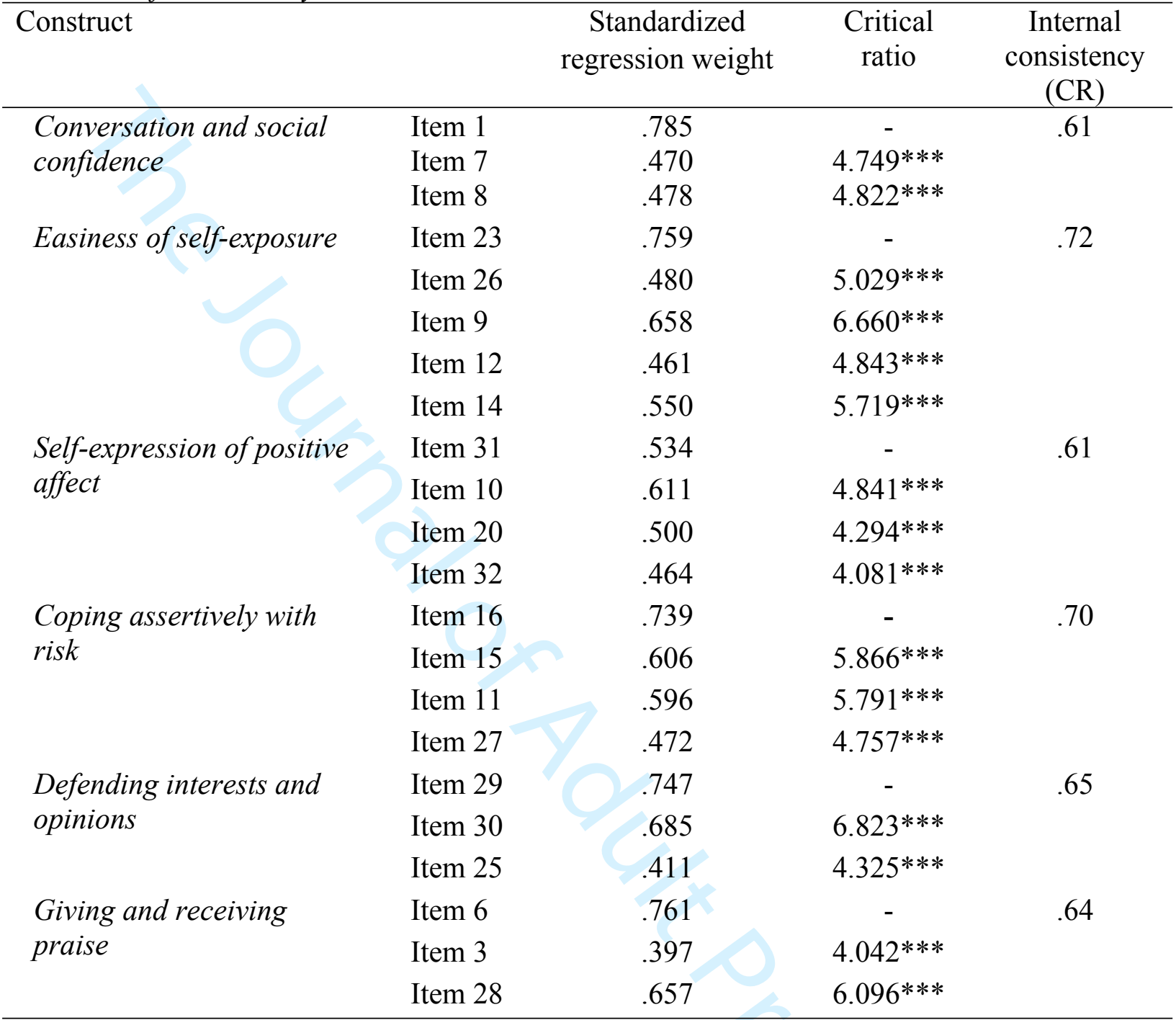

$* * * \mathrm{p}<.001$ 


\section{PORTUGUESE ADAPTATION OF SSI-DEL PRETTE}

Table III

Goodness of fit indicators for the tested models: Model 1 (EFA); Model 2 (theory-driven model $)$ - $(n=146)$

\begin{tabular}{lcccccc}
\hline & $\chi 2$ & $d f$ & $\chi 2 / d f$ & CFI & RMSEA & SRMR \\
\hline Model 1 & $533.317^{* * *}$ & 289 & 1.845 & .690 & .076 & .104 \\
Model 2 & $259.95^{* *}$ & 194 & 1.337 & .902 & .048 & .076
\end{tabular}

$* * \mathrm{p}<.01$

$* * * \mathrm{p}<.001$ 
PORTUGUESE ADAPTATION OF SSI-DEL PRETTE

Table IV

Descriptive statistics of the variables social skills, depression, and empathy

\begin{tabular}{lccc}
\hline & M (SD) & Min & Max \\
& $(\mathrm{N}=212)$ & & \\
\hline Social Skills (SSI-Del-Prette total score) & $76.334(11.279)$ & 51 & 107 \\
F1 - Conversation and social confidence & $3.160(.761)$ & 1.33 & 5.00 \\
F2 - Easiness of self-exposure & $2.835(.736)$ & 1.00 & 4.80 \\
F3 - Self-expression of positive affect & $3.462(.783)$ & 1.75 & 5.00 \\
F4 - Coping assertively with risk & $3.553(.796)$ & 1.50 & 5.00 \\
F5 - Defending interests and opinions & $3.896(.670)$ & 1.67 & 5.00 \\
F6 - Giving and receiving praise & $4.310(.592)$ & 2.67 & 5.00 \\
Depression (BDI) & $7.948(7.391)$ & 0 & 41 \\
Somatic-affective & $5.406(4.775)$ & 0 & 22 \\
Cognitive & $2.382(2.926)$ & 0 & 18 \\
Empathy (IRI) & $114.009(13.26)$ & 79 & 155 \\
Perspective-taking & $4.342(.713)$ & 2.29 & 6 \\
Empathic concern & $4.767(.632)$ & 2.86 & 6 \\
Fantasy & $3.933(.888)$ & 2.29 & 5.86 \\
Personal distress & $3.246(.795)$ & 1.29 & 5.86 \\
\hline
\end{tabular}




\section{PORTUGUESE ADAPTATION OF SSI-DEL PRETTE}

Table V

Pearson correlations between SSI-Del-Prette factor scores and total score, and the total depressive symptomatology (BDI) and its subscales, and the measure of empathy (IRI) and its subscales.

\begin{tabular}{|c|c|c|c|c|c|c|c|}
\hline 8 & $\begin{array}{l}\text { Total } \\
\text { Score }\end{array}$ & Factor 1 & Factor 2 & Factor 3 & Factor 4 & Factor 5 & Factor 6 \\
\hline Depression (BDI) & $-.194 * *$ & $-.151 *$ & $-.244 * *$ & -.084 & $-.196 * *$ & -.031 & .005 \\
\hline Somatic-affective & $-.186 * *$ & $-.151 *$ & $-.234 * *$ & -.094 & $-.167 *$ & -.031 & .001 \\
\hline Cognitive & $-.170 *$ & -.115 & $-.219 * *$ & -.051 & $-.200 * *$ & -.030 & .005 \\
\hline Empathy (IRI) & .123 & .044 & .030 & $.138 *$ & .005 & $.161 *$ & $.226^{* *}$ \\
\hline Fantasy & .080 & .026 & .057 & .042 & .066 & .086 & .068 \\
\hline Empathic concern & $.179 * *$ & $.163 *$ & .054 & $.210^{* *}$ & -.037 & $.171 *$ & $.320 * *$ \\
\hline Perspective-taking & $.314^{* *}$ & $.210^{* *}$ & $.150 *$ & $.259 * *$ & $.155^{*}$ & $.356^{* *}$ & $.277 * *$ \\
\hline Personal distress & $-.221 * *$ & $-.241 * *$ & $-.170 *$ & -.116 & $-.172 *$ & $-.167 *$ & -.040 \\
\hline
\end{tabular}

Note: Factor 1 - Conversation and social confidence; Factor 2 - Easiness of self-exposure;

Factor 3 - Self-expression of positive affect; Factor 4 - Coping assertively with risk; Factor 5

- Defending interests and opinions; Factor 6 - Giving and receiving praise 